\title{
Amphetamine abuse and acute thrombosis of left circumflex coronary artery
}

\author{
Eyad Khattab, Asaad Shujaa
}

\begin{abstract}
Introduction: Currently, amphetamine abuse is a widespread problem. While the use of recreational drugs is more common in young populations, drug abuse within elderly populations is increasing, though largely unrecognized. The exact nature and dose of recreational drugs are difficult to identify when a patient presents requiring urgent care, notably amphetamine-induced acute coronary syndrome (ACS). Case Report: A 54-year-old male smoker presented with classical anginal chest pain after using amphetamines. Electrocardiography (ECG) showed T-wave inversion in leads I, aVL, and V4-V6. Laboratory data revealed total creatine kinase (CK) level 1759 IU/L, CK-MB 87 IU/L, and a troponin-I of $13.38 \mathrm{ng} / \mathrm{mL}$. A diagnosis of non-ST elevation myocardial infarction (NSTEMI) was made. The emergency room physician commenced the NSTEMI protocol, but the patient experienced worsening chest pain unresponsive to nitrates or morphine, with no change in the ECG pattern. The cardiologist decided to proceed with percutaneous coronary intervention. Coronary angiography revealed $100 \%$ stenosis in the proximal portion of the left circumflex artery, with a large clot burden. The artery was stented with excellent results. Later testing showed a positive urine toxicology screen
\end{abstract}

Eyad Khattab ${ }^{1}$, Asaad Shujaa

Affiliations: ${ }^{1} \mathrm{MD}, \mathrm{MPH}$, Demonstrator, Department of Emergency Medicine, King Khalid University Hospital, King Saud University, Riyadh, Saudi Arabia. Resident, Department of Internal Medicine, University of Toledo Medical Center, Toledo, Ohio, United States of America.

Corresponding Author: Eyad Khattab, P.O. Box 7805, Riyadh, SAUDI ARABIA 11472; Ph:+966-503327350; Fax: +966-14672439; Email: eyad.khattab@yahoo.com

Received: 12 April 2013

Accepted: 04 May 2013

Published: 01 December 2013 for amphetamines. Conclusion: Regardless of the age or gender of the patient, asking questions about stimulant drugs use is crucial with anginal chest pain presentation. Drug abuse is not only for young males but older males and females are also susceptible, and can have unique responses to amphetamine abuse. In this case, amphetamine abuse caused myocardial ischemia due to blood clot formation.

Keywords: Amphetamine, Left Circumflex Coronary Artery, Non-ST elevation myocardial infraction (NSTEMI)

\section{$* * * * * * * * *$}

Khattab E, Shujaa A. Amphetamine abuse and acute thrombosis of left circumflex coronary artery. International Journal of Case Reports and Images 2013;4(12):698-701.

$$
* * * * * * * * *
$$

doi:10.5348/ijcri-2013-12-414-CR-8

\section{INTRODUCTION}

Currently, amphetamine abuse is a universal problem. Drug abuse is more common in young population. However, the use of recreational drugs by elderly populations is largely unrecognized and ignored, but increasing [1]. The prevalence of illicit drug use in general populations is difficult to identify due to the covert nature of the activity, especially in one of the most conservative societies, Saudi Arabia, which is tightly surrounded by tradition and religious conservatism. Furthermore, the exact nature and dose of recreational drugs are difficult to establish when a patient presents need urgent care.

As the name suggests, sympathomimetic drugs such as amphetamine work by activating the sympathetic nervous system. As a result, heart rate increases and the 
oxygen supply decreases, causing the oxygen demand of the heart to increase. Serious cardiovascular problems are more common among male users than female, although amphetamine-induced acute coronary syndrome (ACS) is an infrequent occurrence. Acute occlusion of the left circumflex artery (LCX) is complicated to diagnose. Patients having this condition rarely present with STEMI and are not likely to have percutaneous coronary intervention (PCI) [2]. A review of 220 articles reported the activation of the sympathetic nervous system because of amphetamine use can cause myocardial infarction (MI) secondary to coronary artery spasm, and concluded the induction of coronary vasospasm was the likely underlying mechanism of amphetamine-related acute MI [3]. The blood supply to the heart occurs during the diastolic phase of the cardiac cycle unlike other body organs that get their blood supply during the systolic phase of the heart cycle [4]. Moreover, amphetamine is known to increase blood pressure, platelet aggregation, and trigger atherosclerotic plaque rupture [5].

\section{CASE REPORT}

A 54-year-old male, known to have bronchial asthma (mild) well controlled with albuterol inhaler, was brought by his family to our emergency medicine department three hours after the onset of pressure like chest pain, which was central and radiated to the left arm. The patient reported taking an oral dose of amphetamine about seven hours before the presentation. The patient told that the chest pain was neither decreased nor increased by anything. The pain was associated with shortness of breath, nausea and vomiting. The patient had no history of palpitation, cough, wheezing, abdominal pain or back pain. He had no history of similar symptoms before, such as ischemic heart disease, diabetes mellitus, hypertension, hyperlipidemia, or atrial fibrillation. He had no family history of similar symptoms or coronary artery disease. He was not on any medication. He was not allergic to anything. He smoked one pack of cigarettes per day over the last 10 years. He used amphetamine tablets occasionally and had no history of drinking alcohol. At the time of arrival to the hospital, his blood pressure was 137/94 $\mathrm{mmHg}$, heart rate was 77 beat per minute, respiratory rate was 17 breaths per minute, oral temperature was $37.2^{\circ} \mathrm{C}$ and oxygen saturation was $99 \%$ on room air. Generally, he appeared in severe respiratory distress, but alert and oriented. Cardiovascular examination revealed first and second heart sounds were within normal limits, point of maximum impulse was not displaced, and no rub, murmur or gallop sounds were exhibited. His lungs were clear to auscultation bilaterally.

A 12-lead electrocardiogram showed a regular sinus rhythm (79/min) and T-wave inverted in lead I, aVL, (V4V6). The patient had no previous ECG, echo, stress, or lipid profile reports for comparison Because of his lack of prior related symptoms. Laboratory data showed total creatine kinase (CK) level 1759 IU/L, CK-MB level 87U/L, and troponin-I level $13.38 \mathrm{ng} / \mathrm{mL}$, a urine toxic screening test was positive for amphetamine.

Based on the history, physical examinations and investigations, the diagnosis of non-ST elevation myocardial infarction (NSTEMI) was made. The patient was given aspirin $324 \mathrm{mg}$ chew, clopidogrel $300 \mathrm{mg}$ per oral, morphine sulfate $2 \mathrm{mg}$ IV every 10 minutes as needed, subcutaneous low molecular weight heparin $60 \mathrm{mg} \mathrm{(1} \mathrm{mg/}$ $\mathrm{kg}$ ) every 12 hours, and nitroglycerin infusion (10 to 20 $\mu \mathrm{g} / \mathrm{min}$ ). The patient began to experience a worsening angina pain and was not responding to treatment. However, there were no ECG changes from previous tests. The cardiologist decided to do percutaneous coronary intervention (PCI) with approximately 11 hours spanning from the presentation to emergency room visit. Coronary arteriography revealed a $100 \%$ stenosis in the proximal portion with large clot burden at LCX coronary artery. Finally, stent inflation was used with excellent results.

He was discharged from the hospital after one week with orders to take baby aspirin per oral once a day and

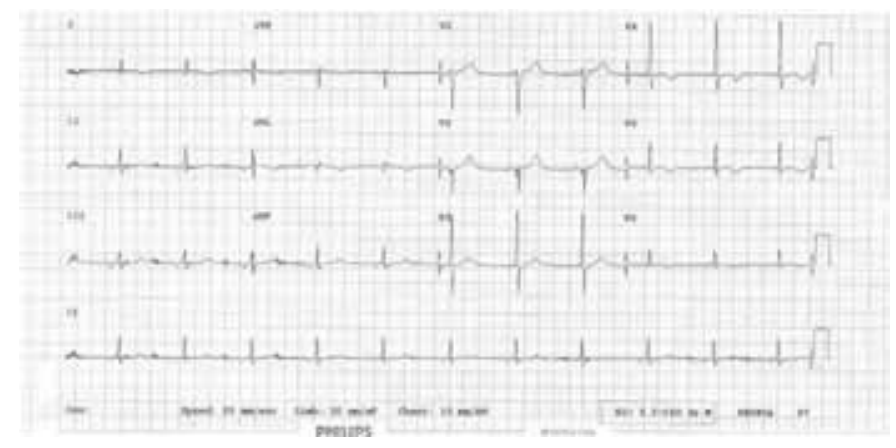

Figure 1: ECG showing T-wave inverted in lead I, aVL, (V4-V6).

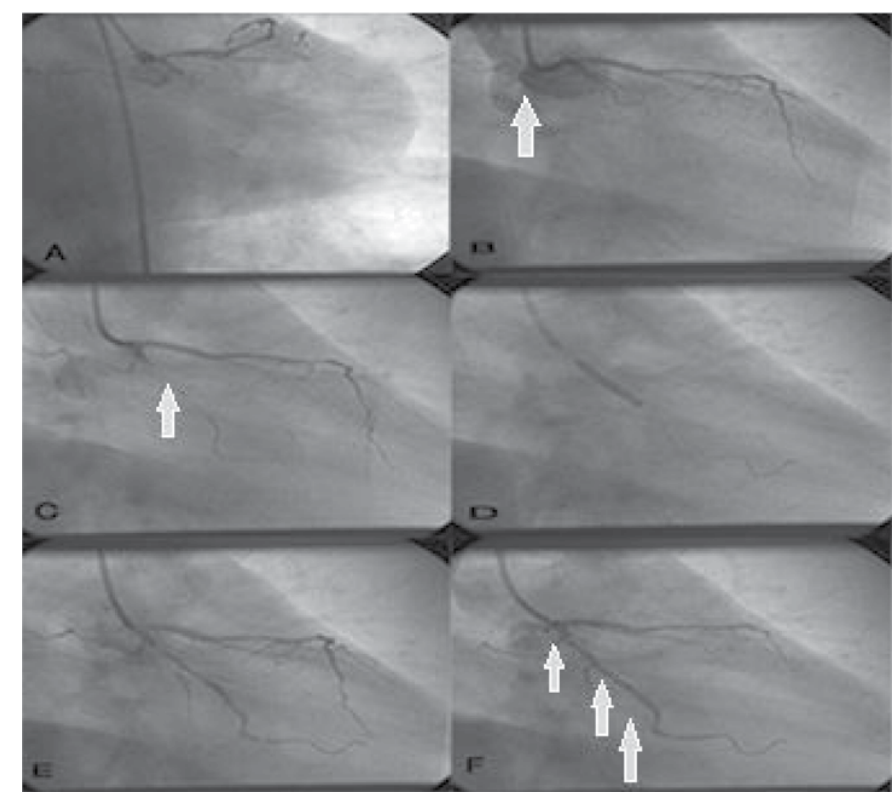

Figure 2: Left coronary angiograph (A, B) Showing full occlusion of left circumflex coronary artery at proximal portion, (B, C) Showing left circumflex coronary artery during stenting, (E, F) Showing patent left circumflex coronary artery after successful stenting. 
clopidogrel $75 \mathrm{mg}$ per oral once a day for six months. Additionally, his medications for bronchial asthma were maintained and he was given an appointment for the cardiac clinic after one week. At follow-up, his blood pressure, lipid profile, and fasting blood sugar were within the normal range.

\section{DISCUSSION}

Cardiovascular problems related to amphetamine use are common. However, most of the cases and population studies in literature concerning drug-induced acute myocardial infarction (AMI) have identified young male patients presenting with elevated ST levels and vasospasms in the left anterior descending artery and/or right coronary artery. What is unique in the present case is the age of the patient, the apparent contributing factors of the AMI, and the location. To our knowledge, there are no publications of amphetamine-induced NSTEMI with selective thrombosis of the LCX and very little focus on oral amphetamine abuse in older adults. According to a population-based observational study, amphetamine abuse contributes to AMI among persons aged 18-44 years, but does not address the incidence among those older than 44 years [5]. Another study of the frequency of acute coronary symptoms due to amphetamine use among patients aged between $32-48$ years [6]. Thus, the age of our 54-year-old patient is unique among literature regarding coronary symptoms due to amphetamine use.

Moreover, the lack of vasospasms and the presence of thrombosis in our case are unusual in literature. The mechanism of drug-induced MI is usually associated with coronary spasms [3]. One exception in literature is the case of a young male patient who presented with acute MI and tested positive for amphetamine. An arteriogram showed acute thrombosis, but early PCI did not help and the patient died later [3]. Our patient was fortunate to have survived. Additionally, many cases of drug-induced AMI show ST-segment elevation, for instance a young male who presented to the emergency room with chest pain after taking Captagon and showed ST elevation due to a narrowing in the proximal portion of the left anterior descending (LAD) artery [7]. However, LCX occlusions, as in our case, do not usually result in elevated ST segments [8].

While LCX occlusions are usually NSTEMI, it is rare for the cardiovascular problems among amphetamine users to be located in the LCX artery in the first place. In contrast, cases of narrowing in the LAD artery [7] and the right coronary artery due to amphetamine use are not unusual [9]. In a rare case, screening of the LCX artery showed thrombosis, but it was secondary to thrombosis of the larger LAD artery [10]. The underlying reason for the rarity of amphetamine-induced LCX thrombosis is speculative, but perhaps it is related to age and pre-existing cardiovascular issues. Exposure to amphetamine may trigger AMI thrombotic occlusion at the site of multiple 'vulnerable' plaques, while most amphetamine abusers are young men who are less likely to have vulnerabilities in the LCX artery. Due to the confluence of unique factors regarding advanced age, the MI mechanism, and the location of the problem, we find this case of amphetamine-induced AMI to be of particular interest for understanding the range of possible cardiovascular issues we may encounter in our emergency room.

\section{CONCLUSION}

This case demonstrates why asking questions about stimulant drugs use is crucial with anginal chest pain presentation, even for an older patient. Drug abuse is not only for young adults and men but middle aged, older persons and women are also susceptible, and can present unique amphetamine-induced acute coronary syndrome etiology. In some cases, as in this present case, sympathomimetic drugs may cause myocardial ischemia due to blood clot formation.

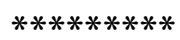

\section{Acknowledgements}

Acknowledgment is owed to Dr. Sabry Elmalah for his help diagnosing and treating the patient and to Clayton Chiarelott for proofreading and editing the article.

\section{Author Contributions}

Eyad Khattab - Conception and design, Acquisition of data, Analysis and interpretation of data, Drafting the article, Critical revision of the article, Final approval of the version to be published

Asaad Shujaa - Conception and design, Acquisition of data, Drafting the article, Final approval of the version to be published

\section{Guarantor}

The corresponding author is the guarantor of submission.

\section{Conflict of Interest}

Authors declare no conflict of interest.

\section{Copyright}

(C) Eyad Khattab et al. 2013; This article is distributed under the terms of Creative Commons attribution 3.0 License which permits unrestricted use, distribution and reproduction in any means provided the original authors and original publisher are properly credited. (Please see www.ijcasereportsandimages.com/copyright-policy.php for more information.)

\section{REFERENCES}

1. Beynon CM, McVeigh J, Roe BA. Problematic drug use, aging and older people: Trends in the age of 
drug users in northwest England. Ageing Society 2007;27:799-810.

2. From AM, Best PJ, Lennon RJ, Rihal CS, Prasad A. Acute myocardial infarction due to left circumflex artery occlusion and significance of ST-segment elevation. Am J Cardiol 2010 Oct 15;106(8):1081-5.

3. El Menyar AA. Drug-induced myocardial infarction secondary to coronary artery spasm in teenagers and young adults. Journal of Postgraduate Medicine 2006 Jan-Mar;52(1):51-6.

4. Heusch G. Heart rate in the pathophysiology of coronary blood flow and myocardial ischaemia: Benefit from selective bradycardic agents. British Journal of Pharmacology 2008 Apr;153(8):1589-601.

5. Westover AN, Nakonezny PA, Haley RW. Acute myocardial infarction in young adults who abuse amphetamines. Drug Alcohol Depend 2008 Jul 1;96(1-2):49-56.

6. Turnipseed SD, Richards JR, Kirk JD, Diercks DB, Amsterdam EA. Frequency of acute coronary syndrome in patients presenting to the emergency department with chest pain after methamphetamine use. Journal of Emergency Medicine 2003 May;24(4):369-73.

7. Uluçay A, Arpacik Kargi C, Aksoy MF. Acute myocardial infarction associated with Captagon use. Anadolu Kardiyol Derg 2012 Mar;12(2):182-5.

8. Stribling WK, Kontos MC, Abbate A, et al. Left circumflex occlusion in acute myocardial infarction (from the National Cardiovascular Data Registry). The American journal of cardiology 2011 Oct 1;108(7):959-63.

9. Furst SR, Fallon SP, Reznik GN, Shah PK. Myocardial infarction after inhalation of methamphetamine. The New England Journal of Medicine 1990 Oct 18;323(16):1147-8.

10. Lan WR, Yeh HI, Hou CJY, Chou YS. Acute Thrombosis of Double Major Coronary Arteries Associated with Amphetamine Abuse. Acta Cardiologica Sinica 2007;23(4):268-72.
Access full text article on other devices

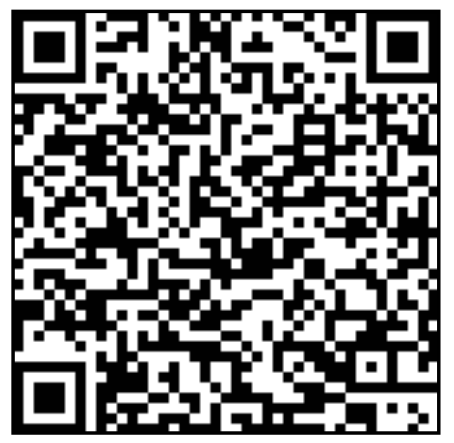

Access PDF of article on other devices

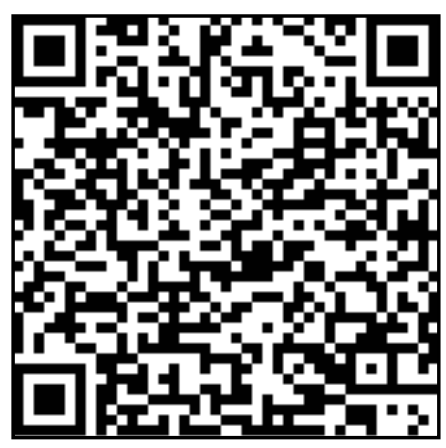

